\title{
Acai, cacao and maca extracts: Anticancer activity and growth inhibition of microbial triggers of selected autoimmune inflammatory diseases
}

\author{
Xiaohong Wang ${ }^{1,2}$, Jiayu Zhang ${ }^{1,2}$, Ian Edwin Cock ${ }^{1,3^{*}}$ \\ 'School of Natural Sciences, Griffith University, Brisbane, AUSTRALIA. \\ ${ }^{2}$ School of Pharmacy, Nanjing University of Chinese Medicine, Nanjing, CHINA. \\ ${ }^{3}$ Environmental Futures Research Institute, Griffith University, Brisbane, AUSTRALIA.
}

\begin{abstract}
Background: The consumption of high antioxidant foods has been linked with a decreased incidence of some cancers and inflammatory diseases. Some high antioxidant foods also inhibit the growth of a variety of bacterial pathogens. Despite this, the high antioxidant 'superfoods' acai, cacao and maca are yet to be adequately tested for anticancer activity or the ability to inhibit the growth of bacterial triggers of autoimmune inflammatory diseases. Materials and Methods: Freeze dried acai, cacao and maca powders were extracted and tested for antimicrobial activity using a modified disc diffusion assay and the MICs were determined. Inhibitory activity against $\mathrm{CaCo} 2$ and HeLa cancer cell lines was evaluated using colorimetric cell proliferation assays. Toxicity was evaluated using an Artemia franciscana nauplii bioassay. Results: The acai, cacao and maca extracts displayed broad spectrum antibacterial activity, inhibiting the growth of all of the bacteria screened, although generally with only low efficacy. The ethyl acetate extracts were more potent bacterial growth inhibitors than were the corresponding methanolic and aqueous extracts. The inhibitory activity of the acai and maca ethyl acetate extracts against $P$. mirabilis was particularly noteworthy, with MIC values $<1000 \mu \mathrm{g} / \mathrm{mL}$. The aqueous and methanolic extracts of all fruits had only low bacterial growth inhibitory activity. In contrast, the aqueous extracts of cacao and maca were the most effective at inhibiting proliferation of the colorectal cancer cell line
\end{abstract}

CaCo2 (aqueous maca extract I $\mathrm{I}_{50}=1800 \mu \mathrm{g} / \mathrm{mL}$ ) and HeLa cervical cancer cell growth, (aqueous cacao extract $I C_{50}$ values $1810 \mu \mathrm{g} / \mathrm{mL}$ ). All extracts were non-toxic, with $\mathrm{LC}_{50}$ values substantially $>1000 \mu \mathrm{g} / \mathrm{mL}$. Conclusion: These studies demonstrate that the aqueous cacao and maca extracts have appreciable inhibitory activity against some cancer cell lines and that the acai and maca ethyl acetate extracts were moderate inhibitors of the growth of bacteria associated with selected autoimmune inflammatory disorders. Furthermore, the toxicity studies indicate that they are safe for therapeutic usage. All other extracts were inactive or of low activity towards the cancer and bacterial cells.

Key words: Euterpe oleracea, Lepidium meyenii, Theobroma cacao, Autoimmune inflammatory disease, Rheumatoid arthritis, Ankylosing spondylitis, Multiple sclerosis, Cancer.

Correspondence:

Ian Edwin Cock, School of Natural Sciences, Griffith University, Brisbane, AUSTRALIA.

Phone no: +61 7 37357637; Fax: +61 737355282

E-mail: I.Cock@griffith.edu.au (I. E. Cock)

DOI : $10.5530 /$ pc.2016.4.3

\section{INTRODUCTION}

A diet rich in antioxidants is associated with a decreased incidence of several chronic diseases including cancer, ${ }^{1}$ cardiovascular diseases, ${ }^{2}$ neural degeneration, ${ }^{3}$ diabetes and obesity. ${ }^{4}$ Many plant constituents have strong antioxidant capacities ${ }^{5}$ and may protect cellular constituents against oxidative damage through the scavenging of free radicals, thereby averting their deleterious effects on nucleic acids, proteins, and lipids. ${ }^{5}$ Some phytochemicals may also interact directly with receptors or enzymes involved in signal transduction, ${ }^{6}$ thereby playing a specific role in human physiology via modulation of the cellular redox state.

The relationship between cellular redox state and cancer progression has been particularly well studied and cellular oxidative stress has been linked with several types of cancer. ${ }^{7,8}$ Thus, it is possible that the high antioxidant contents of some plants may inhibit cancer formation and/or progression. Studies into the antioxidant/pro-oxidant effects of extracts from various plant species have demonstrated that the ability of a plant extract to exert antioxidant activity depends on multiple factors. Some antioxidant compounds may function as either an antioxidant or an oxidant, with their action being dependent upon their concentration. ${ }^{9}$ For example, the Aloe vera (L.) Brum.f. anthraquinone aloe emodin exerts antioxidant behaviour at lower concentrations, yet acts as a pro-oxidant at high concentrations. ${ }^{9}$ In contrast, a different anthraquinone (aloin) has an antioxidant effect at higher concentrations, yet a pro-oxidant effect at low concentrations. Thus, extracts containing these compounds may act as either antioxidants or as oxidants, dependent on differing levels of the various constituents, and on their ratios. Thus, although many plant species have very high antioxidant contents, it is possible that the individual components may act as either antioxidants or as oxidants and thus may also be effective in the treatment of cancer, as well as in its prevention at different concentrations. Similar pro-oxidant effects have been reported for other antioxidant phytochemicals including flavonoids ${ }^{10}$ and tannins. ${ }^{11}$ The pro-oxidant/antioxidant effect of plant extracts is due to a balance between the free radical scavenging activities and reducing power of their phytochemical components.

Recent studies have also demonstrated the inhibitory activity of many plant extracts against a wide panel of pathogenic bacteria. ${ }^{12-14}$ Furthermore, potent growth inhibition has been reported for several high antioxidant fruits ${ }^{15-17}$ and culinary herbs. ${ }^{18}$ Particularly noteworthy, Terminalia ferdinandiana (Kakadu plum), Tasmannia lanceolata (mountain pepperberry) and several Syzygium spp. (which are often referred to as 'superfoods' due to their extremely high antioxidant capacities) are potent growth inhibitors of microbial triggers of rheumatoid arthritis (Proteus mirabilis), ${ }^{19}$ ankylosing spondylitis (Klebsiella pneumoniae ${ }^{20}$ and multiple sclerosis (Acinetobacter baylyi and Pseudomonas aeruginosa). ${ }^{21}$ Therefore these plants have potential in the prevention and treatment of autoimmune inflammatory diseases in genetically susceptible individuals. Furthermore, the phytochemistry of some of these plants indicates that they may also 
have therapeutic effects on downstream inflammatory events including cytokine production. ${ }^{22}$ Due to the pleuripotent effects of these plants, they may be particularly useful in the treatment of inflammatory disease. Surprisingly, despite studies highlighting the potential of some high antioxidant fruits and the recent public awareness of the benefits of high antioxidant 'superfoods', many are yet to be systematically evaluated for their therapeutic potential towards many stages of chronic diseases such as cancer and autoimmune inflammatory diseases. The fruit of Euterpe oleracea Mart. (acai berry) has been highlighted as having one of the highest antioxidant capacities of any plant. ${ }^{23}$ Of particular note, acai berry had exceptionally high superoxide $\left(\mathrm{O}_{2}{ }^{-}\right)$scavenging activity (1614 units/g). ${ }^{23}$ Indeed, acai berry had by far the highest reported $\mathrm{O}_{2}{ }^{-}$ scavenging capacity of any food tested in that study. The same study also reported substantial scavenging activity towards peroxy-nitrite and hydroxyl radicals. Interestingly, the acai berries also inhibited cyclooxygenase enzymes (COX-1 and COX-2), indicating that they may also directly affect inflammatory functions. Similarly, Theobroma cacao L. (cacao) beans are a polyphenol rich food which is recognised as a good source of antioxidants. ${ }^{24,25}$ The high procyanidin content of cacao has been identified as being responsible for its high antioxidant capacity. ${ }^{26}$ Interestingly, cacao consumption has been linked with a reduction of pro-inflammatory mediators and thus has potential in the treatment of inflammation. ${ }^{27}$ Lepidium meyenii Walp. (maca) is cruciferous vegetable native to Peru which is reputed to improve energy and modulate cellular responses to oxidative stress due to its high antioxidant capacity. ${ }^{28}$ This study examines the anti-proliferative activity of extracts prepared from commercially obtained freeze dried acai berry, cacao and maca powders against $\mathrm{HeLa}$ and $\mathrm{CaCo} 2$ cancer cell lines. Furthermore, the growth inhibitory activity of the acai, cacao and maca extracts were tested against some bacterial triggers of rheumatoid arthritis (Proteus mirabilis), ankylosing spondylitis (Klebsiella pneumoniae) and multiple sclerosis (Acinetobacter baylyi and Pseudomonas aeruginosa).

\section{MATERIALS AND METHODS}

Pure raw organic Euterpe oleracea Mart. (acai berry), Lepidium meyenii Walp. (maca) and Theobroma cacao L. (cacao) fruits were obtained from Swisse Nutraceuticals, Australia as vacuum sealed dried powders. Voucher samples have been stored in the School of Natural Sciences, Griffith University. The powdered fruits were extracted by standardised methods. ${ }^{29}$ Briefly, an amount of $1 \mathrm{~g}$ of powdered plant material was weighed into each of five tubes and five different extracts were prepared by adding $50 \mathrm{~mL}$ of methanol, water, ethyl acetate, chloroform, or hexane respectively. All solvents were obtained from Ajax, Australia and were AR grade. The dried powders was extracted in each solvent for $24 \mathrm{hrs}$ at $4^{\circ} \mathrm{C}$ with gentle shaking. The extracts were filtered through filter paper (Whatman No. 54) under vacuum, followed by drying by rotary evaporation in an Eppendorf concentrator 5301. The resultant dry extracts were weighed and redissolved in $10 \mathrm{~mL}$ deionised water containing $1 \%$ DMSO.

\section{Qualitative phytochemical studies}

Phytochemical analysis of the acai, cacao and maca extracts for the presence of saponins, phenolic compounds, flavonoids, phytosterols, triterpenoids, cardiac glycosides, anthraquinones, tannins and alkaloids was conducted by previously described assays. ${ }^{30-32}$

\section{Antioxidant capacity determination}

The antioxidant capacity of each sample was assessed using the DPPH free radical scavenging method ${ }^{30,33}$ with modifications. Briefly, DPPH solution was prepared fresh each day as a $400 \mu \mathrm{M}$ solution by dissolving DPPH (Sigma) in AR grade methanol (Ajax, Australia). The initial absorbance of the DPPH solution was measured at $515 \mathrm{~nm}$ using a Molecular Devices, Spectra Max M3 plate reader and did not change significantly throughout the assay period. A $2 \mathrm{~mL}$ aliquot of each extract was evaporated and the residue resuspended in $2 \mathrm{~mL}$ of methanol. Each extract was added to a 96-well plate in amounts of 5, 10, 25, 50, $75 \mu \mathrm{L}$ in triplicate. Methanol was added to each well to give a volume of $225 \mu \mathrm{L}$. A volume of $75 \mu \mathrm{L}$ of the fresh DPPH solution was added to each well for a total reaction volume of $300 \mu \mathrm{L}$. A blank of each extract concentration, methanol solvent, and DPPH was also performed in triplicate. Ascorbic acid was prepared fresh and examined across the range 0-25 $\mu \mathrm{g}$ per well as a reference and the absorbances were recorded at $515 \mathrm{~nm}$. All tests were performed in triplicate and triplicate controls were included on each plate. The antioxidant capacity based on DPPH free radical scavenging ability was determined for each extract and expressed as $\mu \mathrm{g}$ ascorbic acid equivalents per gram of original plant material extracted.

\section{Antibacterial screening}

\section{Test microorganisms}

All media was supplied by Oxoid Ltd., Australia. Reference strains of Acinetobacter baylyi (ATCC33304), Klebsiella pneumoniae (ATCC31488), Proteus mirabilis (ATCC21721) and Pseudomonas aeruginosa (ATCC39324) were purchased from American Tissue Culture Collection, USA. All other clinical microbial strains were obtained from the School of Natural Sciences teaching laboratory, Griffith University. All stock cultures were subcultured and maintained in nutrient broth at $4^{\circ} \mathrm{C}$.

\section{Evaluation of antimicrobial activity}

Antimicrobial activity of all plant extracts was determined using a modified disc diffusion method. ${ }^{34-36}$ Briefly, $100 \mu \mathrm{L}$ of the test bacteria were grown in $10 \mathrm{~mL}$ of fresh nutrient broth until they reached a count of approximately $10^{8}$ cells $/ \mathrm{mL}$ as determined by direct microscopic determination. 100 microliters of microbial suspension was spread onto the agar plates. The extracts were tested using $5 \mathrm{~mm}$ sterilised filter paper discs. Discs were impregnated with $10 \mu \mathrm{L}$ of the test sample, allowed to dry and placed onto inoculated plates. The plates were allowed to stand at $4^{\circ} \mathrm{C}$ for $2 \mathrm{hrs}$ before incubation with the test microbial agents. Plates inoculated with the bacterial species Klebsiella pneumoniae, Proteus mirabilis and Pseudomonas aeuroginosa were incubated at $30^{\circ} \mathrm{C}$ for $24 \mathrm{hrs}$, then the diameters of the inhibition zones were measured in millimetres. Plates inoculated with Acinetobacter baylyi were incubated at $37^{\circ} \mathrm{C}$ for $24 \mathrm{hrs}$, then the diameters of the inhibition zones were measured. All measurements were to the closest whole millimetre. Each antimicrobial assay was performed in at least triplicate. Mean values $( \pm$ SEM) are reported in this study. Standard discs of ampicillin $(2 \mu \mathrm{g})$ were obtained from Oxoid Ltd., Australia and served as positive controls for antibacterial activity. Filter discs impregnated with $10 \mu \mathrm{L}$ of distilled water were used as a negative control.

\section{Minimum inhibitory concentration (MIC) determination}

The minimum inhibitory concentration (MIC) of the acai, cacao and maca extracts were determined by the disc diffusion method across a range of doses. ${ }^{34-36}$ The plant extracts were diluted in deionised water across a concentration range of $10 \mathrm{mg} / \mathrm{mL}$ to $0.1 \mathrm{mg} / \mathrm{mL}$. Discs were impregnated with $10 \mu \mathrm{L}$ of the test dilutions, allowed to dry and placed onto inoculated plates. The assay was performed as outlined above and graphs of the zone of inhibition versus concentration were plotted for each extract. Linear regression was used to calculate the MIC values. 


\section{Screen for anticancer bioactivity} Cancer cell lines

The $\mathrm{CaCo} 2$ and HeLa carcinoma cell lines used in this study were obtained from American Type Culture Collection (Rockville, USA). The cells were cultured in Roswell Park Memorial Institute (RPMI) 1640 medium (Life Technologies), supplemented with $20 \mathrm{mM}$ HEPES, $10 \mathrm{mM}$ sodium bicarbonate, $50 \mu \mathrm{g} / \mathrm{mL}$ streptomycin, $50 \mathrm{IU} / \mathrm{mL}$ penicillin, $2 \mathrm{mM}$ glutamine and $10 \%$ foetal calf serum (Life Technologies). The cells were maintained as monolayers in $75 \mathrm{~mL}$ flasks at $37^{\circ} \mathrm{C}, 5 \% \mathrm{CO}_{2}$ in a humidified atmosphere until approximately $80 \%$ confluent.

\section{Evaluation of cancer cell anti-proliferative activity}

Anti-proliferative activity of the extracts was assessed as previously described. ${ }^{30,33}$ Briefly, $1 \mathrm{~mL}$ of trypsin (Sigma) was added to the culture flasks and incubated at $37^{\circ} \mathrm{C}, 5 \% \mathrm{CO}_{2}$ for $15 \mathrm{~min}$ to dislodge the cancer cells. The cell suspensions were then transferred to a $10 \mathrm{~mL}$ centrifuge tube and sedimented by centrifugation. The supernatant was discarded and the cells were resuspended in $9 \mathrm{~mL}$ of fresh media. Aliquots of the resuspended cells ( $70 \mu \mathrm{L}$, containing approximately 5000 cells) were added to the wells of a 96 well plate. A volume of $30 \mu \mathrm{L}$ of the test extracts or cell media (for the negative control) was added to individual wells and the plates were incubated at $37^{\circ} \mathrm{C}, 5 \% \mathrm{CO}_{2}$ for $12 \mathrm{hrs}$ in a humidified atmosphere. A volume of $20 \mu \mathrm{L}$ of Cell Titre 96 Aqueous One solution (Promega) was subsequently added to each well and the plates were incubated for a further $3 \mathrm{hrs}$. Absorbances were recorded at $490 \mathrm{~nm}$ using a Molecular Devices, Spectra Max M3 plate reader. All tests were performed in triplicate and triplicate controls were included on each plate. The antiproliferative activity of each test was calculated as a percentage of the negative control using the following formula:

$$
\text { Proliferation }(\% \text { untreated control })=(\text { Act } / \text { Acc }) \times 100
$$

$\mathrm{A}_{\mathrm{ct}}$ is the corrected absorbance for the test extract (calculated by subtracting the absorbance of the test extract in media without cells from the extract cell test combination) and $\mathrm{A}_{\mathrm{cc}}$ is the corrected untreated control (calculated by subtracting the absorbance of the untreated control in media without cells from the untreated cell media combination).

\section{Toxicity screening}

\section{Reference toxins for biological screening}

Potassium dichromate $\left(\mathrm{K}_{2} \mathrm{Cr}_{2} \mathrm{O}_{7}\right)$ (AR grade, Chem-Supply, Australia) was prepared as a $2 \mathrm{mg} / \mathrm{mL}$ solution in distilled water and was serially diluted in synthetic seawater for use in the Artemia franciscana nauplii bioassay.

\section{Artemia franciscana nauplii toxicity screening}

Toxicity was tested using a modified Artemia franciscana nauplii lethality assay. ${ }^{37-39}$ Briefly, A. franciscana cysts were obtained from North American Brine Shrimp, LLC, USA (harvested from the Great Salt Lake, Utah). Synthetic seawater was prepared using Reef Salt, AZOO Co., USA. Seawater solutions at $34 \mathrm{~g} / \mathrm{L}$ distilled water were prepared prior to use. A mass of $1 \mathrm{~g}$ of $A$. franciscana cysts were incubated in $500 \mathrm{~mL}$ synthetic seawater under artificial light at $25^{\circ} \mathrm{C}, 2000$ Lux with continuous aeration. Hatching commenced within 16-18 h of incubation. Newly hatched A. franciscana (nauplii) were used within $10 \mathrm{~h}$ of hatching. Nauplii were separated from the shells and remaining cysts and were concentrated to a suitable density by placing an artificial light at one end of their incubation vessel and the nauplii rich water closest to the light was removed for biological assays. The extracts and positive control were also serially diluted in artificial seawater for $\mathrm{LC}_{50}$ determination. A volume of $400 \mu \mathrm{L}$ of seawater containing approximately 43 (mean 43.2, n=162, SD 12.7) nauplii were added to wells of a 48 well plate and immediately used for bioassay.
The plant extracts were diluted in seawater for toxicity testing. A volume of $400 \mu \mathrm{L}$ of the diluted plant extracts or the reference toxin was transferred to the wells and incubated at $25 \pm 1^{\circ} \mathrm{C}$ under artificial light (1000 Lux). A negative control ( $400 \mu \mathrm{L}$ seawater) was run in triplicate for each plate. All treatments were performed in triplicate. The wells were checked at regular intervals and the number of dead counted. The nauplii were considered moribund if no movement of the appendages was observed within $10 \mathrm{sec}$. After $48 \mathrm{~h}$ all nauplii were sacrificed and counted to determine the total number per well. The $\mathrm{LC}_{50}$ with $95 \%$ confidence limits for each treatment was calculated using probit analysis.

\section{Statistical analysis}

Data are expressed as the mean \pm SEM of three independent experiments. One way ANOVA was used to calculate statistical significance between control and treated groups with a $P$ value $<0.01$ considered to be statistically significant.

\section{RESULTS}

\section{Liquid extraction yields and qualitative phytochemical screening}

Extraction of $1 \mathrm{~g}$ of freeze dried and vacuum sealed acai, cacao and maca powders with various solvents yielded dried plant extracts ranging from $77 \mathrm{mg}$ (maca ethyl acetate extract) to $695 \mathrm{mg}$ (aqueous acai extract) (Table 1). Generally, water gave the highest yields of extracted material (244-695 mg) compared with the other solvents. Methanol also generally extracted relatively high yields, whilst ethyl acetate extracted substantially lower yields. The dried extracts were resuspended in $10 \mathrm{~mL}$ of deionised water resulting in the extract concentrations shown in Table 1. Qualitative phytochemical screening studies (Table 1) showed that all solvents extracted wide ranges and relatively large amount of phytochemicals. Furthermore, all solvents extracted similar classes of phytochemicals, with polyphenolic compounds and flavonoids predominating. Lower amounts of triterpenoids were also present in most extracts. All extracts were generally devoid of all other classes of phytochemicals or they were present in only low levels.

\section{Antioxidant content}

Antioxidant capacity (expressed as ascorbic acid equivalents) for the acai, cacao and maca extracts are shown in Table 1 . The antioxidant capacity ranged from $1 \mathrm{mg}$ ascorbic acid equivalents per gram of dried plant material extracted (maca ethyl acetate extract) to approximately $16 \mathrm{mg}$ ascorbic acid equivalents per gram of dried plant material extracted (methanolic cacao extract). Whilst slightly lower than the methanolic cacao extract, the methanolic acai extract also had a high antioxidant capacity with approximately $14 \mathrm{mg}$ ascorbic acid equivalents per gram of dried plant material extracted. The antioxidant capacity of all maca extracts, and of the aqueous and ethyl acetate acai and cacao extracts was substantially lower (approximately 1-7 mg ascorbic acid equivalents per $\mathrm{g}$ of plant material extracted).

\section{Antimicrobial activity}

To determine the antimicrobial activity of the crude plant extracts, aliquots $(10 \mu \mathrm{L})$ of each extract were tested in the disc diffusion assay against a panel of bacteria previously identified as microbial triggers of autoimmune inflammatory diseases. Both reference and clinical strains of $P$. mirabilis were inhibited by all of the acai, cacao and maca extracts, albeit with relatively small zones of inhibition (Figure 1). Indeed, all extracts inhibited $P$. mirabilis growth with low to moderate efficacy, with zones of inhibition generally $<8 \mathrm{~mm}$. This does not compare favourably to the ampicillin control, which had zones of inhibition of $12-12.5 \mathrm{~mm}$ against both strains. 
Table 1: The mass of acai, cacao and maca extracts, the concentration after resuspension in deionised water (1\% DMSO) and qualitative phytochemical screenings of solvent extractions

\begin{tabular}{|c|c|c|c|c|c|c|c|c|c|}
\hline & \multicolumn{3}{|c|}{ Acai } & \multicolumn{3}{|c|}{ Cacao } & \multicolumn{3}{|c|}{ Maca } \\
\hline & $M$ & W & $E$ & $M$ & W & $E$ & $M$ & W & $E$ \\
\hline Mass of dried extract (mg) & 245 & 695 & 82 & 139 & 370 & 122 & 159 & 244 & 77 \\
\hline Resuspended extract concentration $(\mathrm{mg} / \mathrm{mL})$ & 24.5 & 69.5 & 8.2 & 13.9 & 37 & 12.2 & 15.9 & 24.4 & 7.7 \\
\hline \multicolumn{10}{|l|}{ Qualitative phytochemical screens } \\
\hline Total phenolics & +++ & +++ & + & +++ & +++ & ++ & +++ & ++ & + \\
\hline Water soluble phenolics & +++ & ++ & + & ++ & ++ & + & ++ & + & - \\
\hline Water insoluble phenolics & +++ & +++ & + & +++ & ++ & ++ & +++ & ++ & + \\
\hline Cardiac glycosides & - & - & - & - & - & - & - & - & - \\
\hline Saponins & - & - & - & - & - & - & + & + & - \\
\hline Triterpenoids & + & + & + & + & - & + & + & - & + \\
\hline Phytosteroids & - & - & - & - & - & - & - & - & - \\
\hline Alkaloids (Mayer test) & - & - & - & - & - & - & - & - & - \\
\hline Alkaloids (Wanger test) & - & - & - & - & - & - & - & - & - \\
\hline Flavanoids & +++ & +++ & ++ & +++ & +++ & ++ & ++ & +++ & + \\
\hline Tannins & + & + & - & - & - & - & - & - & - \\
\hline Free anthraquinones & - & - & - & - & - & - & - & - & - \\
\hline Combined anthraquinones & - & - & - & - & - & - & - & - & - \\
\hline Antioxidant capacity (mg AA equivalency/g powder extracted) & 13.9 & 5.8 & 1.4 & 15.7 & 6.9 & 1.8 & 3.9 & 0.8 & 1 \\
\hline
\end{tabular}

+++ indicates a large response; ++ indicates a moderate response; + indicates a minor response; - indicates no response in the assay; $\mathrm{AA}=$ ascorbic acid; $\mathrm{M}=$ methanolic extract; $\mathrm{W}=$ water extract; $\mathrm{E}=$ ethyl acetate extract.

The acai, cacao and maca extracts also inhibited K. pneumonia reference strains and clinical isolates with similar efficacy (Figure 2). Both K. pneumonia strains were equally susceptible to the extracts. Interestingly, a significant difference was noted between the susceptibility of the reference strain and clinical isolates to the ampicillin control. The inhibition zone of the reference K. pneumonia strain was approximately $3 \mathrm{~mm}$ greater than for the clinical isolate. Whilst zones of inhibition were noted for all of the acai, cacao and maca extracts, these were all $<7.5 \mathrm{~mm}$ in diameter, indicating that the anti-Klebsiella compounds in these extracts were weak, in low concentrations, and/or nonpolar.

The growth inhibition of the A. baylyi reference strain and clinical isolate by acai, cacao and maca extracts was also uniformly low (Figure 3 ). Zones of inhibition $<7 \mathrm{~mm}$ were recorded for all extracts against both the reference and clinical A. baylyi strains (compared to zones of inhibition of approximately $12 \mathrm{~mm}$ for the ampicillin control). Similarly, whilst all of the extracts inhibited $P$. aeruginosa growth, the zones of inhibition ( $<6.5 \mathrm{~mm}$ for all extracts against both the reference strain and clinical isolate) were indicative of weak growth inhibitory activity (Figure 4). However, it is noteworthy that both the P. aeruginosa reference strain and clinical isolate were resistant to ampicillin, with zones of inhibition of only $6 \mathrm{~mm}$.

The antimicrobial efficacy was further quantified by determining the MIC values for each extract against the microbial species which were determined to be susceptible (Table 2). Most of the extracts displayed only low efficacy at inhibiting microbial growth, with MIC values against the susceptible bacteria generally $>2500 \mu \mathrm{g} / \mathrm{mL}(<25 \mu \mathrm{g}$ impregnated in the disc). There were some notable exceptions. The acai ethyl acetate extract had MIC values $<2000 \mu \mathrm{g} / \mathrm{ml}$ against reference strains and clinical isolates of $P$. mirabilis and K. pneumoniae. This extract was particularly good at inhibiting $P$. mirabilis growth with an MIC value of $894 \mu \mathrm{g} / \mathrm{mL}$ (approximately $9 \mu \mathrm{g}$ impregnated in the disc), indicating the potential of this extract in preventing and treating rheumatoid arthritis. The ethyl acetate maca extract also had low MIC values against reference strains and clinical isolates of $P$. mirabilis ( 849 and $712 \mu \mathrm{g} / \mathrm{mL}$ respectively) and may therefore also be useful in the prevention and treatment of rheumatoid arthritis.

\section{Inhibition of cancer cell proliferation}

The acai, cacao and maca extracts were tested against 2 cancer cell lines (CaCo2 colorectal carcinoma cells, Figure 5; HeLa cervical cancer cells, Figure 6) to determine their ability to inhibit cancer cell growth. The aqueous and methanolic extracts generally had the greatest anti-proliferative activity against $\mathrm{CaCo} 2$ cells, with proliferation generally inhibited to $<50 \%$ of the untreated control cell growth (Figure 5). In comparison, the methanolic cacao extract was completely devoid of anti-proliferative activity. Indeed, this extract induced significant $\mathrm{CaCo} 2$ cellular proliferation. The ethyl acetate extracts of all plants also inhibited $\mathrm{CaCo} 2$ cell proliferation, albeit by a lesser percentage. Generally, no significant difference was noted between the corresponding extracts of the different plant samples, each plant inhibiting cellular growth by approximately the same extent. Inhibition of $\mathrm{CaCo} 2$ proliferation by all inhibitory extracts was dose dependent, with the level of inhibitory activity decreasing at lower concentrations.

The acai, cacao and maca extracts also inhibited the proliferation of HeLa cells, albeit with lower efficacy than against the $\mathrm{CaCo} 2$ cells (Figure 6). The methanolic and aqueous cacao extracts were the most potent inhibitors of HeLa cell proliferation, inhibiting growthby approximately 76 and $83 \%$ of the untreated control cell growth respectively. The methanolic maca extract was also a good anti-proliferative agent, inhibiting growth by approximately $63 \%$. Whilst the methanolic and aqueous acai, and the aqueous maca extracts also significantly decreased cell proliferation, they were less potent inhibitors of proliferation, inhibiting proliferation 
Table 2: The MIC values against susceptible bacteria $(\mu \mathrm{g} / \mathrm{mL}), \mathrm{IC}_{50}$ values $(\mu \mathrm{g} / \mathrm{mL})$ against CaCo2 and HeLa cancer cell lines, and the $\mathrm{LC}{ }_{50}$ values $(\mu \mathrm{g} / \mathrm{mL})$ for Artemia franciscana nauplii exposed to acai, cacao and maca extracts

\begin{tabular}{|c|c|c|c|c|c|c|c|c|c|c|}
\hline & & \multicolumn{3}{|c|}{ Acai } & \multicolumn{3}{|c|}{ Cacao } & \multicolumn{3}{|c|}{ Maca } \\
\hline & & M & w & $\mathrm{E}$ & M & w & E & M & w & E \\
\hline \multirow{8}{*}{ 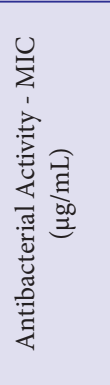 } & P. mirabilis (ATCC:21721) & 2804 & $>10,000$ & 894 & 8225 & $>10,000$ & 2855 & 3090 & 5127 & 849 \\
\hline & P. mirabilis clinical isolate & 3150 & $>10,000$ & 1020 & 6820 & $>10,000$ & 2270 & 3487 & 4763 & 712 \\
\hline & K. pneumoniae (ATCC: 31488) & 3775 & $>10,000$ & 1576 & 2853 & $>10,000$ & 6177 & 6558 & $>10,000$ & 2644 \\
\hline & K. pneumoniae clinical isolate & 4187 & $>10,000$ & 1760 & 2853 & $>10,000$ & 5623 & 7134 & $>10,000$ & 2644 \\
\hline & A. baylyi (ATCC: 33304) & $>10,000$ & $>10,000$ & 5582 & 3924 & $>10,000$ & 6830 & $>10,000$ & $>10,000$ & 3283 \\
\hline & A. baylyiclinical isolate & $>10,000$ & $>10,000$ & 5582 & 3760 & $>10,000$ & 6830 & $>10,000$ & $>10,000$ & 3550 \\
\hline & P. aeruginosa (ATCC39324) & 5118 & $>10,000$ & 2428 & 3766 & 1287 & 7014 & 5106 & $>10,000$ & 3735 \\
\hline & P. aeruginosa clinical isolate & 5118 & $>10,000$ & 3190 & 3766 & 1453 & 7835 & 6335 & $>10,000$ & 5288 \\
\hline$\dot{\bar{U}} \cup^{\circ} \circlearrowleft$ & $\mathrm{CaCo} 2$ cells & 6120 & $>10,000$ & CND & - & 2650 & CND & 3800 & 1800 & CND \\
\hline 莨密 & HeLa cells & CND & 7350 & CND & 2170 & 1810 & CND & 5210 & CND & - \\
\hline 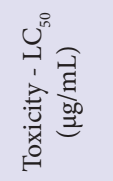 & Artemia franciscana nauplii & 4783 & $>10,000$ & 2145 & 1847 & 4482 & 1259 & 4386 & 3386 & 2730 \\
\hline
\end{tabular}

Numbers indicate the mean MIC, $\mathrm{IC}_{50}$ and $\mathrm{LC}_{50}$ values of triplicate determinations. - indicates no inhibition. CND=although significant inhibition of proliferation was evident, an $\mathrm{IC}_{50}$ value could not be determined as inhibition of cell proliferation did not exceed $50 \%$ at any dose tested. M=methanolic extract; W=aqueous extract; $\mathrm{E}=$ ethyl acetate extract.

only by $8 \%$ (methanolic acai extract) to $48 \%$ (aqueous maca extract). None of the other extracts affected cellular proliferation to a significant extent. Inhibition of HeLa proliferation by all inhibitory extracts was dose dependent, with the level of inhibitory activity decreasing at lower concentrations.

The relative level of anti-proliferative activity was further evaluated by determining the $\mathrm{IC}_{50}$ values (Table 2) for each extract against the $\mathrm{CaCo} 2$ and HeLa cells. In general, the acai, caco and maca extracts all had similar anti-proliferative efficacies. With some notable exceptions, the $\mathrm{IC}_{50}$ values were indicative of only low anti-proliferative activity $\left(\mathrm{IC}_{50}>2500\right.$ $\mu \mathrm{g} / \mathrm{mL})$. However, the aqueous maca $\left(\mathrm{CaCo} 2 \mathrm{IC}_{50}=1800 \mu \mathrm{g} / \mathrm{mL}\right)$ and aqueous cacao extracts $\left(\mathrm{HeLa} \mathrm{IC} \mathrm{IC}_{50}=1810 \mu \mathrm{g} / \mathrm{mL}\right)$ had $\mathrm{IC}_{50}$ values indicative of moderate anti-proliferative activity. Despite displaying significant inhibitory activity, $\mathrm{IC}_{50}$ values could not be determined for several extracts against both cell lines as the levels of inhibition did not exceed $50 \%$ at any dosage tested.

\section{Quantification of toxicity}

The acai, cacao and maca extracts were screened for toxicity in the Artemia nauplii lethality bioassay. For comparison, the reference toxin potassium dichromate was also tested in the bioassay. Potassium dichromate was rapid in its induction of mortality, with mortality evident within 4 hrs of exposure (unpublished results). The acai, cacao and maca extracts were slower at inducing mortality, with $\geq 12$ hrs needed for mortality induction. Despite the slower onset of mortality, all extracts induced mortality significantly above that of the artificial seawater control (Figure 7). Table 2 shows the extract and control toxin concentrations required to achieve $50 \%$ mortality $\left(\mathrm{LC}_{50}\right)$ at various times. As toxicity of crude plant extracts has previously been defined as $24 \mathrm{~h} \mathrm{LC}_{50}$ values $<1000 \mu \mathrm{g} / \mathrm{mL}^{36}$ the measured $\mathrm{LC}_{50}$ values indicate that all acai, caco and maca extracts were nontoxic.

\section{DISCUSSION}

Maintenance of the cellular redox state is required for the normal functioning of living systems. This redox maintenance involves a regulated balance between oxidants and antioxidants. Cells use a variety of different antioxidant mechanisms to help maintain this redox state. ${ }^{40,41}$ These cellular defences include enzymatic antioxidants (superoxide dismutase, catalase, thioredoxin, thioredoxin reductase, glutathione peroxidase and glutathione peroxidase) and nonenzymatic antioxidants (glutathione, vitamins $\mathrm{A}, \mathrm{C}$ and E). Deregulation of the redox balance has been implicated in numerous diseases, including atherosclerosis, diabetes, cirrhosis, ${ }^{42}$ autoimmune disease and chronic inflammation, ${ }^{43}$ neurodegeneration ${ }^{42}$ and cancer, (particularly in tumour initiation and tumour promotion). ${ }^{40,41}$ An understanding of redox regulation is important in identifying new targets for the development of new drugs for cancer prevention and cancer therapy. Epidemiological studies have shown that a diet rich in antioxidants is associated with a decreased incidence of chronic diseases. ${ }^{43}$ Individuals with elevated dietary intakes of nonenzymatic antioxidants such as vitamins $\mathrm{A}, \mathrm{C}$ and $\mathrm{E}$ are less likely to suffer many chronic illnesses and some forms of cancer. ${ }^{43,44}$ High antioxidant levels have also been shown to act as a preventative against the development of neural degeneration. ${ }^{45}$ All of the plant species screened for anti-proliferative activity against cancer cells in our study have been previously shown to have high antioxidant contents ${ }^{23-26,28}$ and are often referred to as 'superfoods' for this reason. Our study generally confirmed the relatively high antioxidant contents of the methanolic and aqueous extracts these plants using a DPPH free radical scavenging assay. Therefore, these 'superfoods' may contribute to reducing oxidative damage via non-enzymatic mechanisms and the scavenging of free radicals. However, other studies indicate that antioxidants may themselves be cytotoxic ${ }^{46}$ and may therefore have potential in preventing the growth of pathogens. Many high antioxidant fruits and herbs have been reported to have good 


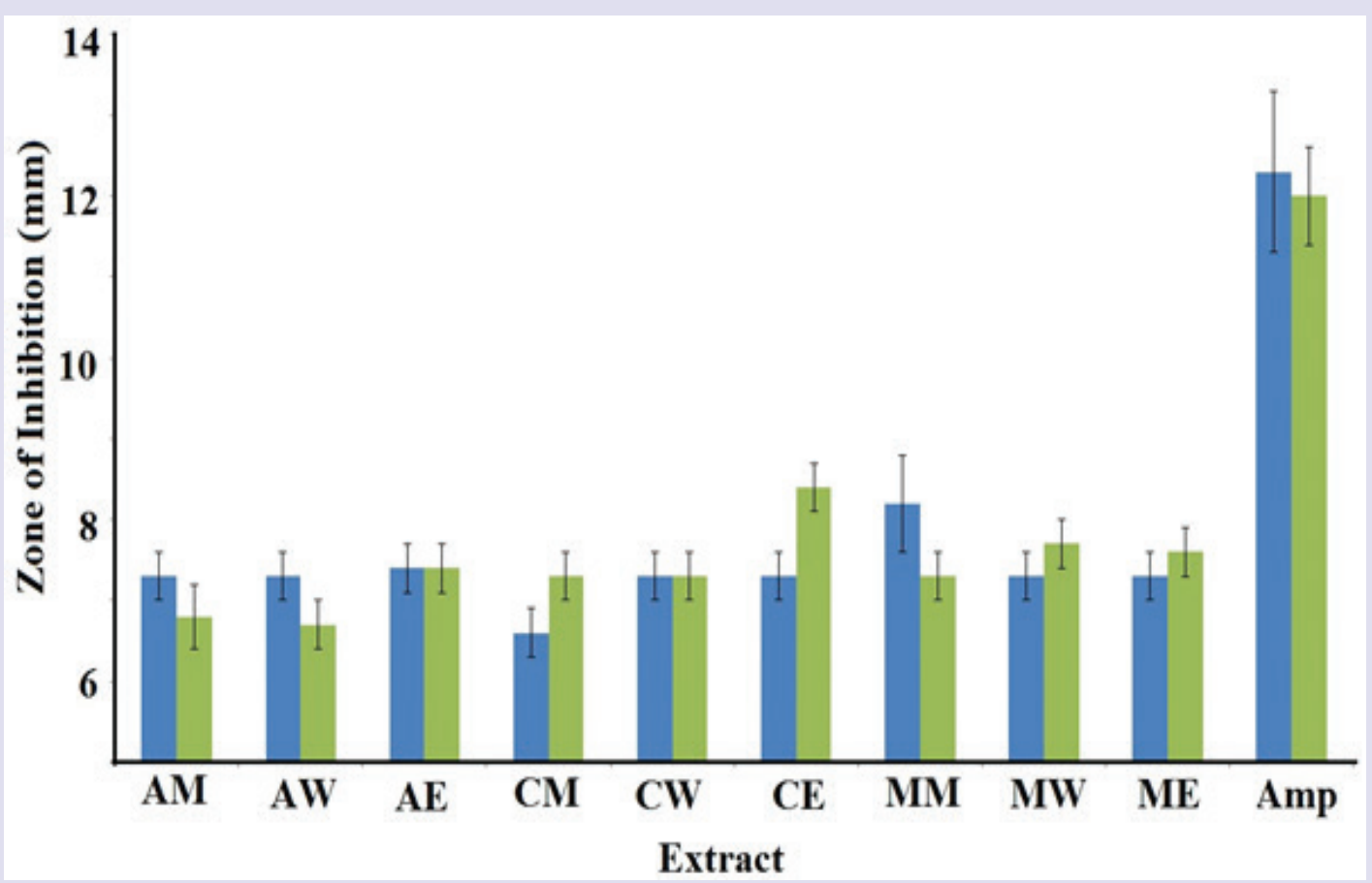

Figure 1: Antibacterial activity of the acai, cacao and maca extracts against $P$. mirabilis measured as zones of inhibition ( $\mathrm{mm}$ ). The blue bars represent the inhibitory activity against the reference strain (ATCC: 21721 ) and the green bars represent the zones of inhibition against the clinical strain. $A M=$ acai methanolic extract; $A W=$ acai water extract; $A E=$ acai ethyl acetate extract; $\mathrm{CA}=$ cacao methanolic extract; $\mathrm{CW}=$ cacao water extract; $\mathrm{CE}=$ cacao ethyl acetate extract; $\mathrm{MM}=$ maca methanolic extract; $\mathrm{MW}=$ maca water extract; $\mathrm{ME}=$ maca ethyl acetate extract; $\mathrm{Amp}=$ ampicillin $(2 \mu \mathrm{g})$ control. Results are expressed as mean zones of inhibition \pm SEM.

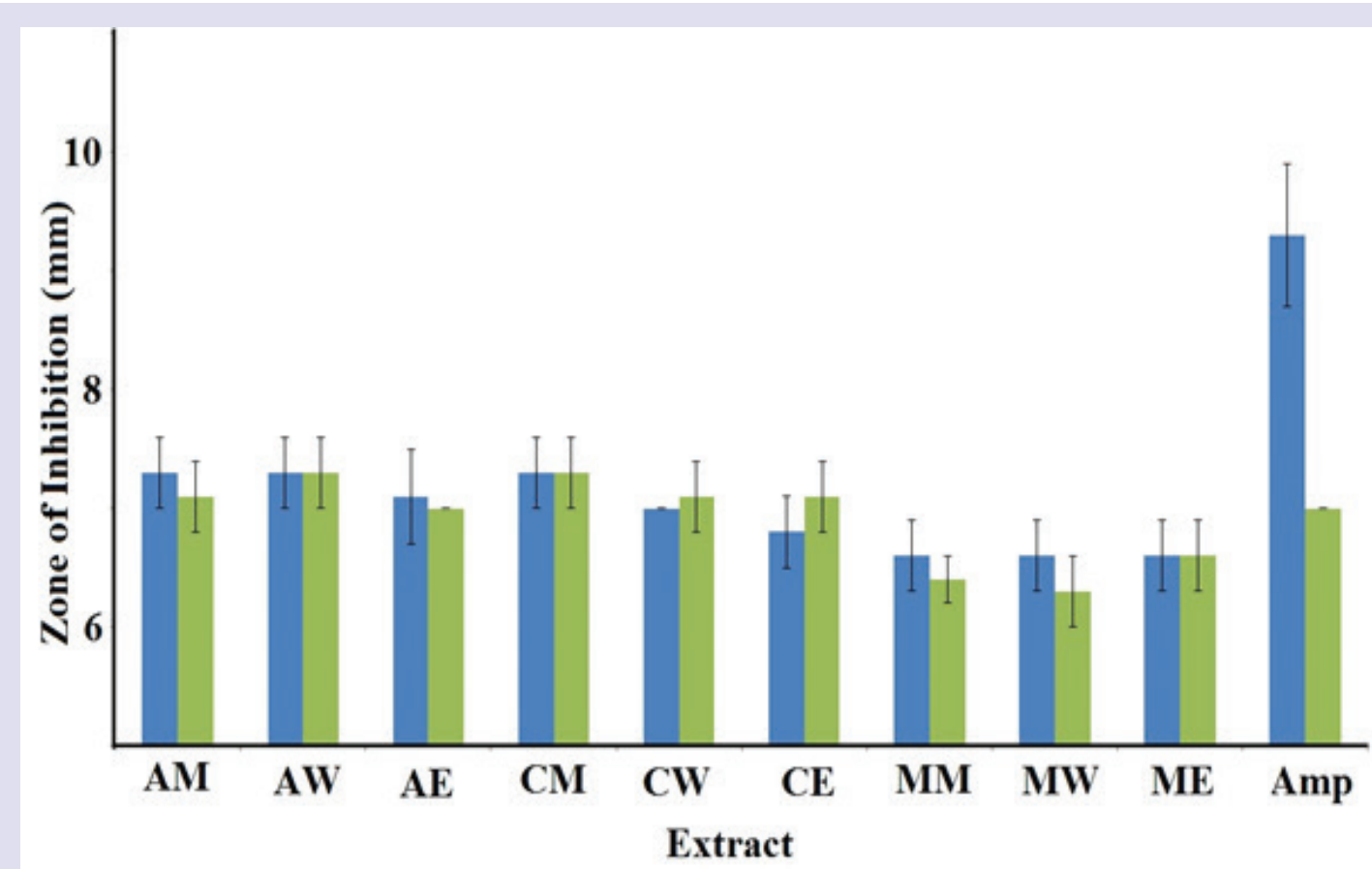

Figure 2: Antibacterial activity of the acai, cacao and maca extracts against $K$. pneumoniae measured as zones of inhibition $(\mathrm{mm}$ ). The blue bars represent the inhibitory activity against the reference strain (ATCC: 31488 ) and the green bars represent the zones of inhibition against the clinical strain. $A M=$ acai methanolic extract; $A W=$ acai water extract; $A E=$ acai ethyl acetate extract; $\mathrm{CA}=$ cacao methanolic extract; $\mathrm{CW}=$ cacao water extract; $\mathrm{CE}=$ cacao ethyl acetate extract; $\mathrm{MM}=$ maca methanolic extract; $\mathrm{MW}=$ maca water extract; $\mathrm{ME}=$ maca ethyl acetate extract; $\mathrm{Amp}=$ ampicillin $(2 \mu \mathrm{g})$ control.

Results are expressed as mean zones of inhibition \pm SEM. 


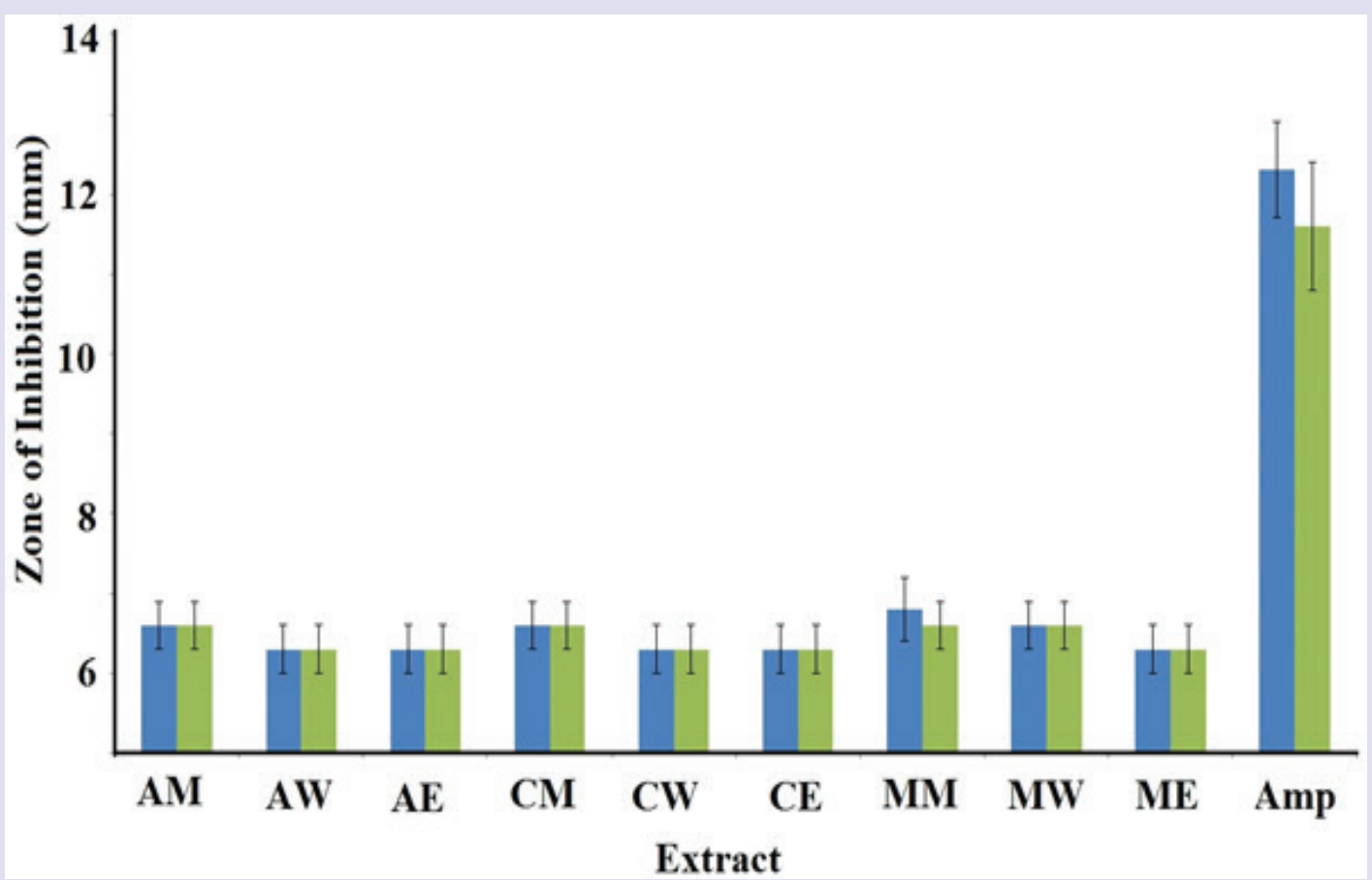

Figure 3: Antibacterial activity of the acai, cacao and maca extracts against $A$. baylyi measured as zones of inhibition ( $\mathrm{mm}$ ). The blue bars represent the inhibitory activity against the reference strain (ATCC: 33304 ) and the green bars represent the zones of inhibition against the clinical strain. $A M=$ acai methanolic extract; $A W=$ acai water extract; $A E=$ acai ethyl acetate extract; $C A=$ cacao methanolic extract; $C W=$ cacao water extract; $C E=$ cacao ethyl acetate extract; $M M=$ maca methanolic extract; $\mathrm{MW}=$ maca water extract; $\mathrm{ME}=$ maca ethyl acetate extract; $\mathrm{Amp}=$ ampicillin $(2 \mu \mathrm{g})$ control. Results are expressed as mean zones of inhibition \pm SEM.

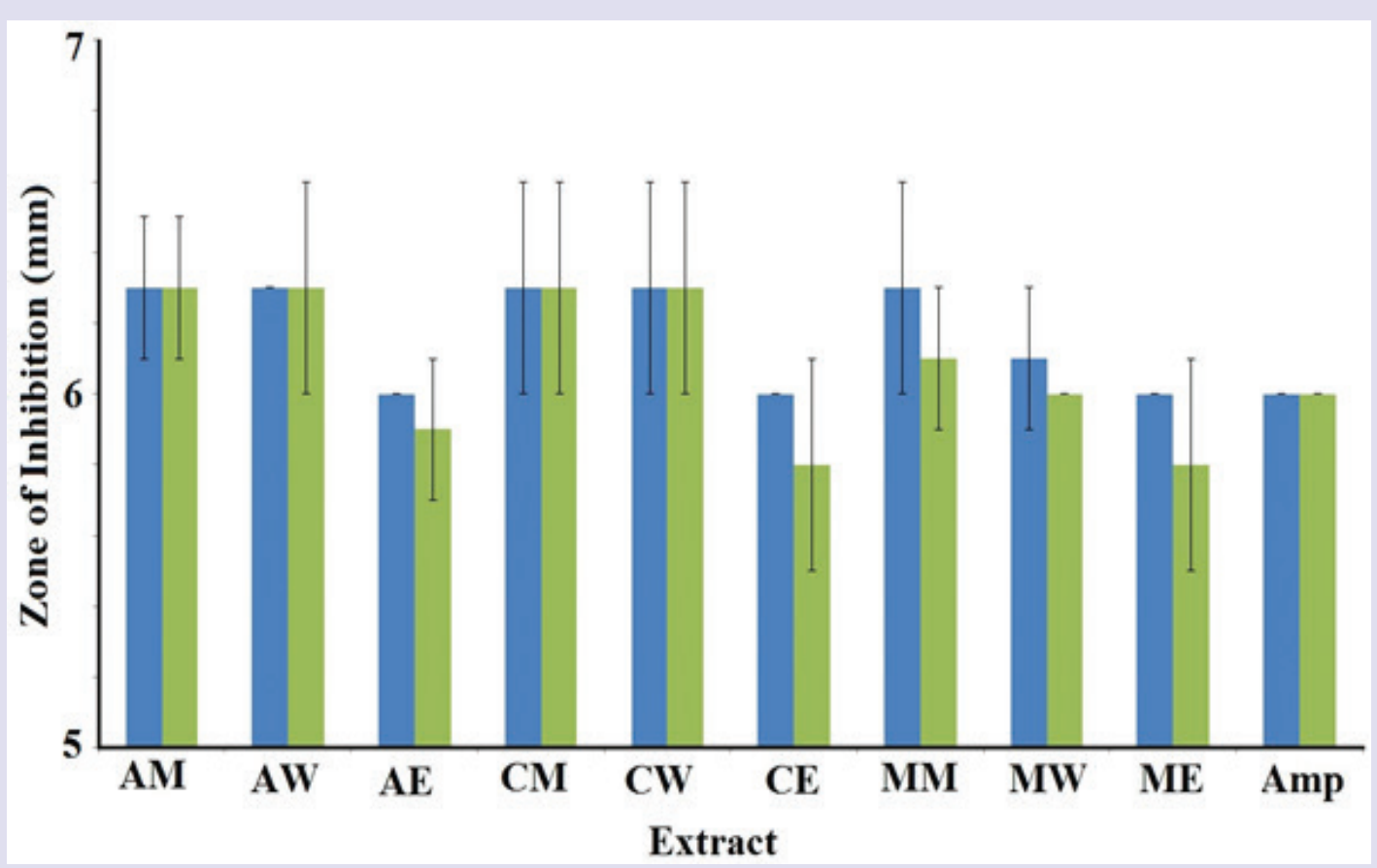

Figure 4: Antibacterial activity of the acai, cacao and maca extracts against $P$. aeruginosa measured as zones of inhibition $(\mathrm{mm}$ ). The blue bars represent the inhibitory activity against the reference strain (ATCC: 31488 ) and the green bars represent the zones of inhibition against the clinical strain. $A M=$ acai methanolic extract; $A W=$ acai water extract; $A E=$ acai ethyl acetate extract; $C A=$ cacao methanolic extract; $C W=$ cacao water extract; $C E=$ cacao ethyl acetate extract; $M M=$ maca methanolic extract; $\mathrm{MW}=$ maca water extract; $\mathrm{ME}=$ maca ethyl acetate extract; $\mathrm{Amp}=$ ampicillin $(2 \mu \mathrm{g})$ control.

Results are expressed as mean zones of inhibition \pm SEM. 


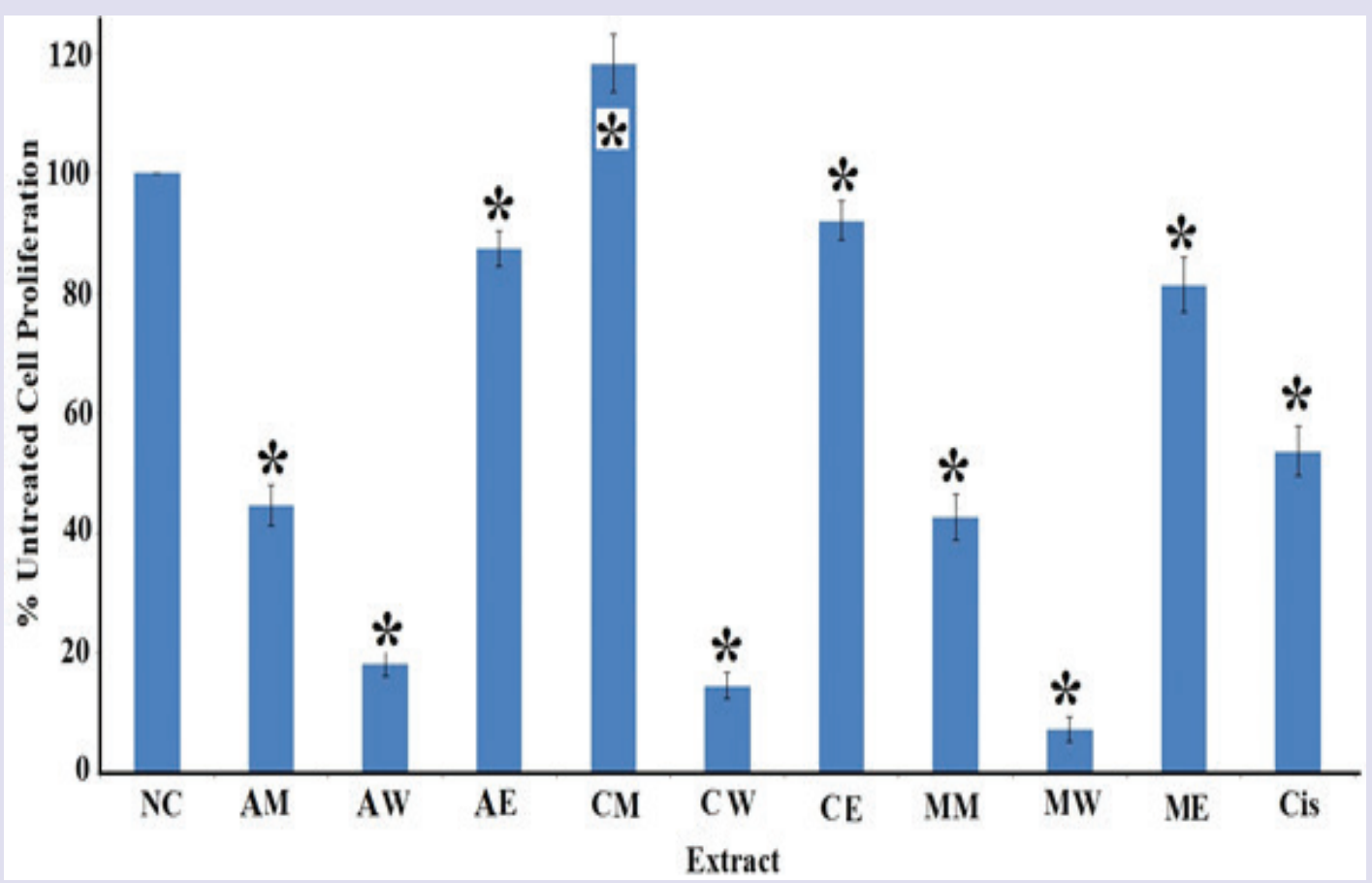

Figure 5: Anti-proliferative activity of the acai, cacao and maca extracts against $\mathrm{CaCo} 2$ cancer cell lines measured as percentages of the untreated control cells. $\mathrm{NC}=$ untreated control; $\mathrm{AM}=$ acai berry methanolic extract; $\mathrm{AW}=$ acai berry aqueous extract; $\mathrm{AE}=$ acai berry ethyl acetate extract; $\mathrm{CM}=$ cacao methanolic extract; $\mathrm{CW}=$ cacao aqueous extract; $\mathrm{CE}=$ cacao ethyl acetate extract; $\mathrm{MM}=$ maca methanolic extract; $\mathrm{MW}=$ aqueous maca extract; $\mathrm{ME}=$ maca ethyl acetate extract; $\mathrm{Cis}=$ cisplatin $(20 \mathrm{mg} / \mathrm{mL})$. Results are expressed as mean percentages \pm SEM of triplicate determinations.

*indicates results that are significantly different to the untreated control $(p<0.01)$.

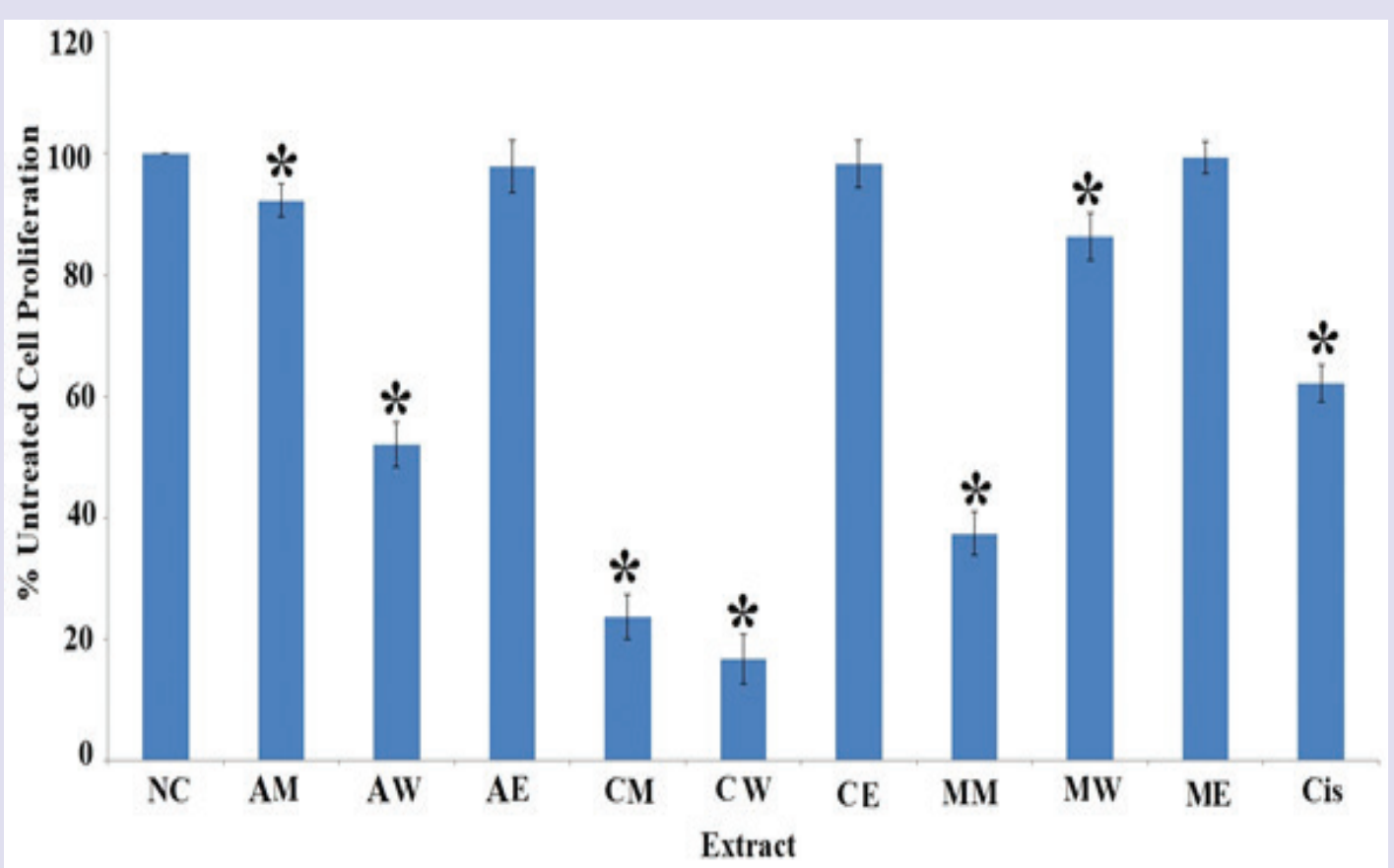

Figure 6: Anti-proliferative activity of the acai, cacao and maca extracts against HeLa cancer cell lines measured as percentages of the untreated control cells. $\mathrm{NC}=$ untreated control; $\mathrm{AM}=$ acai berry methanolic extract; $\mathrm{AW}=$ acai berry aqueous extract; $\mathrm{AE}=$ acai berry ethyl acetate extract; $\mathrm{CM}=$ cacao methanolic extract; $\mathrm{CW}=$ cacao aqueous extract; $\mathrm{CE}=$ cacao ethyl acetate extract; $\mathrm{MM}=$ maca methanolic extract; $\mathrm{MW}=$ aqueous maca extract; $\mathrm{ME}=$ maca ethyl acetate extract; $\mathrm{Cis}=\mathrm{cisplatin}(20 \mathrm{mg} / \mathrm{mL})$. Results are expressed as mean percentages \pm SEM of triplicate determinations.

* indicates results that are significantly different to the untreated control $(p<0.01)$. 


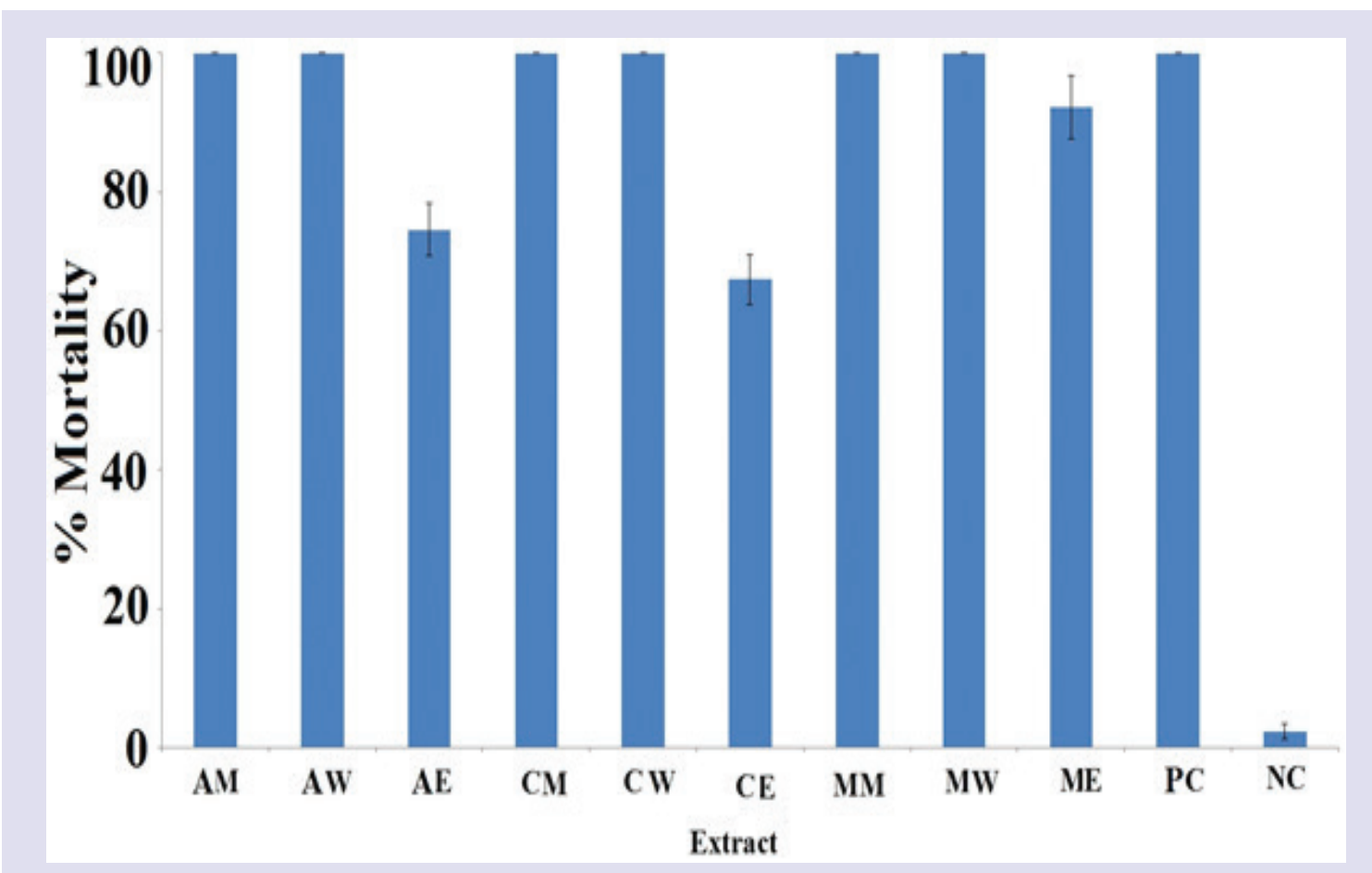

Figure 7: The lethality of the plant extracts towards Artemia franciscana nauplii after $24 \mathrm{hrs}$ exposure. AM=acai berry methanolic extract; $\mathrm{AW}=$ acai berry aqueous extract; $\mathrm{AE}=$ acai berry ethyl acetate extract; $\mathrm{CM}=$ cacao methanolic extract; $\mathrm{CW}=\mathrm{cacao}$ aqueous extract; $C E=$ cacao ethyl acetate extract; $M M=$ maca methanolic extract; $M W=$ =aqueous maca extract; $M E=$ maca ethyl acetate extract; $\mathrm{PC}=$ potassium dichromate control $(1000 \mu \mathrm{g} / \mathrm{mL}) ; \mathrm{NC}=$ seawater control. Results are expressed as mean \pm SEM of triplicate determinations.

antibacterial activities. ${ }^{12-19,21,33,36}$ Given the high antioxidant capacities and 'superfood' status of acai, cacao and maca, surprisingly few studies have examined their ability to inhibit the growth of pathogenic bacteria. Indeed, whilst multiple anecdotal reports are available, we were unable to find any scientific studies screening acai, cacao or maca extracts for the ability to inhibit the growth of $P$. mirabilis, K. pneumoniae, A. baylyi or $P$. aeruginosa. Our findings indicate that whilst all of the extracts screened had growth inhibitory activity, they generally had low efficacy. Thus most of the extracts have negligible effects on the growth of these bacteria. However, the acai and maca ethyl acetate extracts had good bacterial growth inhibitory properties, with their efficacy against $P$. mirabilis particularly noteworthy (MIC values $<1000 \mu \mathrm{g} / \mathrm{mL}$ ). As $P$. mirabilis has been shown to be a trigger for rheumatoid arthritis in genetically susceptible people ${ }^{47}$ these extracts have potential for the prevention and treatment of this disease. Similarly, the same extracts were moderate to good inhibitors of $K$. pnuemoniae growth. K. pnuemoniae is a trigger of ankylosing spondylitis in genetically susceptible people, ${ }^{48}$ indicating further therapeutic uses in individuals with this disease. Furthermore, these extracts were found to be non-toxic in the Artemia nauplii bioassay. The anti-proliferative efficacy of the acai, cacao and maca extracts was also examined against two cancer cell lines in vitro; $\mathrm{CaCo}-2$ (colorectal) and HeLa (cervical). Extracts from other high antioxidant fruits are good inhibitors of cancer cell growth and their anti-proliferative efficacy is often related to the antioxidant capacities of the extracts. ${ }^{18,49}$ In contrast to these previous reports, the anti-proliferative activities of the acai, cacao and maca extracts observed in our study did not correlate with their measured antioxidant capacities. Indeed, the most potent inhibitor of $\mathrm{CaCo} 2$ proliferation was the aqueous maca extract $\left(\mathrm{IC}_{50} 1800 \mu \mathrm{g} / \mathrm{mL}\right)$. The antioxidant capacity of this extract was determined to be $0.8 \mathrm{mg}$ ascorbic acid equivalents per $\mathrm{g}$ of maca powder extracted. This equates to only $0.08 \%$ or the mass of the powder root. This would not be considered a high antioxidant capacity. Similarly, the aqueous cacao extract was the best inhibitor of HeLa proliferation $\left(\mathrm{IC}_{50} 1800 \mu \mathrm{g} / \mathrm{mL}\right.$ ). Whilst this extract has a relatively high antioxidant capacity $(6.9 \mathrm{mg}$ ascorbic acid equivalents per $\mathrm{g}$ of cacao powder extracted), it was substantially lower than the corresponding methanolic extract (15.7 mg ascorbic acid equivalents per $\mathrm{g}$ of cacao powder extracted). Indeed, all methanolic extracts had substantially higher antioxidant capacities than the other extracts for each plant, yet none showed good anti-proliferative activities. This is in contrast to several previous studies which report that the level of antiproliferative activity correlates with antioxidant capacity for several high antioxidant fruits. ${ }^{18,49,50}$

Previous studies have reported antioxidant capacities as high as $660 \mathrm{mg}$ ascorbic acid equivalents (66\%) for methanolic Terminalia ferdinandiana Exell. Extracts, ${ }^{51}$ and 9 (0.9\%), 12 (1.2\%) and $16 \mathrm{mg}$ (1.6\%) ascorbic acid equivalents for Diploglottis australis (G. Don) Radlk (Australian native tamarind), Citrus glauca (Lindl.) Burkill (desert lime) and Podocarpus elatus R.Br. (Illawara plum) respectively. ${ }^{18}$ These studies have reported potent anti-proliferative activity for these extracts and have shown that the activity correlates with antioxidant capacity. ${ }^{18,49}$ Another study also reported a relationship between antioxidant activity and anti-proliferative activity of apples against $\mathrm{CaCo} 2$ cells. ${ }^{50}$ It was suggested that the anti-proliferative activity was due to the combination of phenolic acids and flavonoids. This correlates with the results observed in the qualitative phytochemical analysis of this report. Phenolic and flavonoid compounds were observed to be present in high levels all of the extracts that displayed strong anti-proliferative activity, and often in lower levels in the extracts that did not block cell proliferation. Flavonoids are believed 
to protect cells from disease by shielding lipids, proteins and DNA from oxidative damage. ${ }^{52}$ Previous in vitro bioactivity studies of flavonoids have demonstrated anti-inflammatory, antioxidant, and anticancer activity. ${ }^{52}$ The results of this study indicate that the acai, cacao and maca extracts have bacterial growth inhibitory activity and ability to block cancer cell proliferation. The good antibacterial activity of acai and maca ethyl acetate extracts and the cancer cell anti-proliferative activity of the aqueous cacao and maca extracts indicates their potential in the treatment of rheumatoid arthritis and some cancers. Further research is warranted to extend these studies. Surprisingly, all other extracts were of only low activity and generally would be expected to have negligible beneficial therapeutic effects on bacteria growth inhibition and cancer cell proliferation. Surprisingly, this was also true for the highest antioxidant capacity methanolic extracts. As extracts with $\mathrm{LC}_{50}$ values greater than $1000 \mu \mathrm{g} / \mathrm{mL}$ in the Artemia nauplii bioassay have been defined as being nontoxic, ${ }^{39}$ all extracts studied were deemed nontoxic. However, whilst these extracts have therapeutic potential, caution is needed before they can be applied to medicinal purposes and further toxicity evaluation using normal human cell lines is required.

\section{CONCLUSION}

All extracts were determined to be nontoxic and are therefore likely to be safe for therapeutic use. However, the therapeutic benefit of the acai, cacao and maca extracts in inhibiting proliferation of $\mathrm{CaCo} 2$ and HeLa cancer cell lines and for blocking the bacterial triggers of some autoimmune diseases is likely to be negligible as only have moderate to low bacterial growth inhibitory and anticancer activities were noted for most extracts.

\section{ACKNOWLEDGEMENTS}

Financial support for this work was provided by the Environmental Futures Research Institute and the School of Natural Sciences, Griffith University.

\section{CONFLICTS OF INTEREST}

The authors report no conflicts of interest.

\section{ABBREVIATIONS USED}

DMSO: Dimethyl sulfoxide; $\mathbf{I C}_{50}$ : The concentration required to achieve a $50 \%$ reduction in bioactivity; $\mathbf{L C}_{50}$ : The concentration required to achieve 50\% mortality; MIC: Minimum inhibitory concentration.

\section{REFERENCES}

1. Hertog MG, Bueno-de-Mesquita HB, Fehily AM. Fruit and vegetable consumption and cancer mortality in the caerphilly study. Cancer Epidemiology, Biomarkers and Prevention. 1996;5(9):673-7.

2. Vita JA. Polyphenols and cardiovascular disease: Effects on endothelial and platelet function. American Journal of Clinical Nutrition. 2005;81(1):292S-7S.

3. Youdim KA, Spencer JPE, Schroeter H. Dietary flavonoids as potential neuroprotectans. Biological Chemistry. 2002;383(3-4):503-19.

4. Tsuda T, Horio F, Uchida K. Dietary cyanidin 3-O-b- D-glucoside-rich purple corn colour prevents obesity and ameliorates hyperglycemia in mice. Journal of Nutrition. 2003;133(7):2125-30.

5. Rice-Evans C, Miller N, Paganga G. Antioxidant properties of phenolic compounds. Trends in Plant Science. 1997;2(4):152-9.

6. Moskaug JO, Carlsen H, Myhrstad MCW. Polyphenols and glutathione synthesis regulation. American Journal of Clinical Nutrition. 2005;81(1):277-83S.

7. Brown NS, Bicknell R. Hypoxia and oxidative stress in breast cancer. Oxidative stress: its effects on the growth, metastatic potential and response to therapy of breast cancer. Breast Cancer Research. 2001;3(5):323-7.

8. Tome ME, Baker AF, Powis G. Catalase-overexpressing thymocytes are resistant to glucocorticoid-induced apoptosis and exhibit increased net tumor growth. Cancer Research. 2001;61(6):2766-73.

9. Cock IE. Problems of reproducibility and efficacy of bioassays using crude extracts, with reference to Aloe vera. Pharmacognosy Communications. 2011;1(1):52-62. DOI: 10.5530/pc.2011.1.3
10. Rahman A, Shahabuddin M, Hadi SM. Complexes involving quercetin, DNA and Cu(II). Carcinogenesis. 1990;11(11):2001-3.

11. Singh S, Farhan AS, Ahmad A. Oxidative DNA damage by capsaicin and dihydrocapsaicin in the presence of Cu(II). Cancer Letters. 2001;169(2):139-46.

12. Cock IE, Mohanty S. Evaluation of the antibacterial activity and toxicity of Terminalia ferdinandiana fruit extracts. Pharmacognosy Journal. 2011;3(2):72-9. DOI: $10.5530 / p j .2011 .20 .14$

13. Courtney R, SirdaartaJ, Matthews B, etal. Tannin components and inhibitory activity of Kakadu plum leaf extracts against microbial triggers of autoimmune inflammatory diseases. Pharmacognosy Journal. 2015;7(1):18-31. DOI: 10.5530/ pj.2015.7.2

14. Wright MH, Matthews B, Greene AC, et al. Growth inhibition of the zoonotic bacteria Bacillus anthracis by high antioxidant Australian plants: New leads for the prevention and treatment of anthrax. Pharmacognosy Communications. 2015;5(3):173-89. DOI: 10.5530/pc.2015.3.3

15. Sautron C, Cock IE. Antimicrobial activity and toxicity of Syzygium australe and Syzygium luehmannii fruit extracts. Pharmacognosy Communications. 2014;4(1):53-60. DOI: 10.5530/pc.2014.1.8

16. Chikowe G, Mpala L, Cock IE. Antibacterial activity of selected Australian Syzygium species. Pharmacognosy Communications. 2013;3(4):77-83. DOI: 10.5530/pc.2013.4.11

17. WinnettV, BoyerH, Sirdaarta J, etal.The potential of Tasmannialanceolataasanatural preservative and medicinal agent: antimicrobial activity and toxicity. Pharmacognosy Communications. 2014;4(1):42-52. DOI: 10.5530/pc.2014.1.7

18. Maen A, Cock IE. Inhibitory activity of Australian culinary herb extracts against the bacterial triggers of selected autoimmune diseases. Pharmacognosy Communications. 2015;5(2):130-9. DOI: 10.5530/pc.2015.2.4

19. Sirdaarta J, Matthews B, Cock IE. Kakadu plum fruit extracts inhibit growth of the bacterial triggers of rheumatoid arthritis: Identification of stilbene and tannin components. Journal of Functional Foods. 2015;17:610-20. DOI: 10.1016/j.jff.2015.06.019

20. Cock IE, van Vuuren SF. The potential of selected South African plants with antiKlebsiella activity for the treatment and prevention of ankylosing spondylitis. Inflammopharmacology. 2014;23(1):21-35. DOI: 10.1007/s10787-014-0222-z

21. Sirdaarta J, Matthews B, White A, et al. GC-MS and LC-MS analysis of Kakadu plum fruit extracts displaying inhibitory activity against microbial triggers of multiple sclerosis. Pharmacognosy Communications. 2015;5(2):100-15. DOl: 10.5530/pc.2015.2.2

22. Tan AC, Hou DX, Konczak I. Native Australian fruit polyphenols inhibit COX-2 and iNOS expression in LPS-activated murine macrophages. Food Research International 2011;44(7):2362-7.

23. Schauss AG, Wu X, Prior RL. Antioxidant capacity and other bioactivities of the freeze-dried Amazonian palm berry, Euterpe oleraceae mart.(acai). Journal of Agricultural and Food Chemistry. 2006;54(22):8604-10.

24. Schinella G, Mosc, S, Cienfuegos-Jovellanos E. Antioxidant properties of polyphenol-rich cocoa products industrially processed. Food Research International. 2010;43(6):1614-23.

25. Lee KW, Kim YJ, Lee HJ. Cocoa has more phenolic phytochemicals and a higher antioxidant capacity than teas and red wine. Journal of Agricultural and Food Chemistry. 2003;51(25):7292-5.

26. Cádiz-Gurrea ML, Lozano-Sánchez J, Contreras-Gámez M. Isolation, comprehensive characterization and antioxidant activities of Theobroma cacao extract. Journal of Functional Foods. 2014; 10:485-98.

27. Sies $H$, Schewe T, Heiss C. Cocoa polyphenols and inflammatory mediators The American Journal of Clinical Nutrition. 2005;81(1):304S-12S.

28. Sandoval M, Okuhama NN, Angeles FM. Antioxidant activity of the cruciferous vegetable Maca (Lepidium meyenii). Food Chemistry. 2002;79(2):207-13.

29. Boyer H, Cock IE. Evaluation of the potential of Macadamia integriflora extracts as antibacterial food agents. Pharmacognosy Communications. 2013;3(3):53-62. DOI: $10.5530 / p c .2013 .3 .10$

30. Arkhipov A, Sirdaarta J, Rayan $P$, et al. An examination of the antibacterial, antifungal, anti-Giardial and anticancer properties of Kigelia africana fruit extracts. Pharmacognosy Communications. 2014;4(3):62-76. DOI: 10.5530/pc.2014.3.7

31. Kalt FR, Cock IE. Gas chromatography-mass spectroscopy analysis of bioactive Petalostigma extracts: Toxicity, antibacterial and antiviral activities. Pharmacognosy Magazine. 2014;10(Suppl 1):S37-49. DOI: 10.4103/09731296.127338

32. Vesoul J, Cock IE. The potential of Bunya Nut as an antibacterial food agent Pharmacognosy Communications. 2012;2(1):72-9. DOI: 10.5530/pc.2012.1.13

33. Jamieson N, Sirdaarta J, Cock IE. The anti-proliferative properties of Australian plants with high antioxidant capacities against cancer cell lines. Pharmacognosy Communications. 2014;4(4):71-82. DOI: 10.5530/pc.2014.4.8

34. Cock IE, van Vuuren SF. Anti-Proteus activity of some South African medicinal plants: Their potential for the treatment and prevention of rheumatoid arthritis. Inflammopharmacology. 2014;22(1):23-36. DOI: 10.1007/s10787013-0179-3.

35. Maen A, Cock IE. Inhibitory activity of high antioxidant Australian native fruits against the bacterial triggers of selected autoimmune diseases. Pharmacognosy Communications. 2015;5(1):48-59. DOI: 10.5530/pc.2015.1.5 
36. Cock IE, Winnett V, Sirdaarta J, et al. The potential of selected Australian medicinal plants with anti-Proteus activity for the treatment and prevention of rheumatoid arthritis. Pharmacognosy Magazine. 2015;42(Supp 1):S190-S208. DOI: 10.4103/0973-1296.157734

37. Cock IE. Assessment of the toxicity of selected Australian native plant extracts using the Artemia franciscana nauplii bioassay. Internet Journal of Toxicology. 2008;5(2).

38. Ruebhart D, Wickramasinghe W, Cock IE. Protective efficacy of the antioxidants vitamin EandTroloxagainst Microcystis aeruginosaand microcystin-LR in Artemia franciscana nauplii. Journal of Toxicology and Environmental Health Part A. 2009; 72(24):1567-75. DOI: 10.1080/15287390903232459

39. Cock IE, Ruebhart DR. Comparison of the brine shrimp nauplii bioassay and the ToxScreen-II test for the detection of toxicity associated with Aloe vera (Aloe barbadensis Miller) leaf extract. Pharmacognosy Research. 2009;1(2):98-101.

40. Mohanty S, Cock IE. The chemotherapeutic potential of Terminalia ferdinandiana: Phytochemistry and bioactivity. Pharmacognosy Reviews. 2012;6(11):29-36. DOI: 10.4103/0973-7847.95855

41. Cock IE. The phytochemistry and chemotherapeutic potential of Tasmannia lanceolata (Tasmanian pepper): A review. Pharmacognosy Communications. 2013;3(4):13-25. DOI: 10.5530/pc.2013.4.3

42. Halliwell B. Vitamin C. Antioxidant or pro-oxidant in vivo? Free Radical Research. 1996;25(5):439-54.

43. Potter JD. Cancer prevention: Epidemiology and experiment. Cancer Letters. $1997 ; 114(1-2): 7-9$
44. Hertog MG, Bueno-de-Mesquita HB, Fehily AM. Fruit and vegetable consumption and cancer mortality in the caerphilly study. Cancer Epidemiology Biomarkers and Prevention. 1996;5(9):673-7.

45. Youdim KA, Spencer JP, Schroeter H. Dietary flavonoids as potential neuroprotectans. Biological Chemistry. 2002;383(3-4):503-19.

46. Sirdaarta J, Cock IE. Vitamin E and Trolox ${ }^{\mathrm{TM}}$ reduce toxicity of Aloe barbadensis Miller juice in Artemia franciscana nauplii but individually are toxic at high concentrations. The Internet Journal of Toxicology. 2008; 5(1).

47. Ebringer A, Rashid T. Rheumatoid arthritis is an autoimmune disease triggered by Proteus urinary tract infection. Clinical and Developmental Immunology. 2006;13(1):41-8

48. Ebringer A, RashidT, Wilson C. Ankylosing spondylitis as an auto-immune disease linked to intestinal Klebsiella infection: prospects for a new therapeutic approach. Current Rheumatology Reviews. 2006;2:55-68.

49. Jamieson N, Sirdaarta J, Cock IE. The anti-proliferative properties of Australian plants with high antioxidant capacities against cancer cells. Pharmacognosy Communications. 2014;4(4);71-82. DOI: 10.5530/pc.2014.4.8

50. Eberhardt, MV, Lee CY, Liu RH. Nutrition: Antioxidant activity of fresh apples. Nature. 2000;405(6789):903-4.

51. Rayan $\mathrm{P}$, Matthews $\mathrm{B}, \mathrm{McD}$ onnell $\mathrm{PA}$, et al. Terminalia ferdinandiana extracts as inhibitors of Giardia duodenalis proliferation: a new treatment for giardiasis. Parasitology Research. 2015;114(7):2611-20. DOI: 10.1007/s00436-015-4465-4

52. Chen $A Y$, Chen YC. A review of the dietary flavonoid, kaempferol on human health and cancer prevention. Food Chemistry. 2013;138(4):2099-107.

\section{PICTORIAL ABSTRACT}

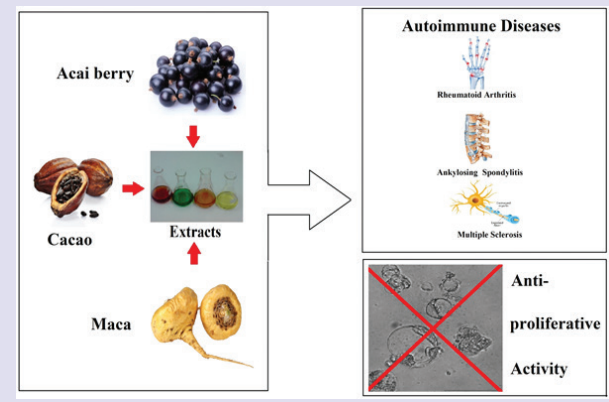

\section{SUMMARY}

- Acai, cacao and maca extracts displayed low potency broad spectrum growth inhibitory activity against some bacterial triggers of autoimmune inflammatory diseases.

- The antibacterial activity of acai and maca ethyl acetate extracts were the most potent bacterial growth inhibitors ( $P$. mirabilis MIC values $<1000$ $\mu \mathrm{g} / \mathrm{mL})$.

- The aqueous maca extract was the most effective inhibitor of colorectal cancer cell line $\mathrm{CaC} 22$ growth $\left(\mathrm{IC}_{50}=1800 \mu \mathrm{g} / \mathrm{mL}\right)$.

- The aqueous cacao extract was the most effective inhibitor of HeLa cervical cancer cell growth $\left(\mathrm{IC}_{50}\right.$ values $\left.1810 \mu \mathrm{g} / \mathrm{mL}\right)$

- All acai, cacao and maca extracts were nontoxic.

\section{ABOUT AUTHORS}

Dr lan Cock leads a research team in the Environmental Futures Research Institute and the School of Natural Sciences at Griffith University, Australia. His research involves bioactivity and phytochemical studies into a variety of plant species of both Australian and international origin including Aloe vera, South Asian and South American tropical fruits, as well as Australia plants including Scaevola spinescens, Pittosporum phylliraeoides, Terminalia ferdinandiana (Kakadu plum), Australian Acacias, Syzygiums, Petalostigmas and Xanthorrhoea johnsonii (grass trees). This range of projects has resulted in nearly 200 scientific publications in a variety of peer reviewed journals. 